\title{
Self-Structure and Self-Esteem Stability: The Hidden Vulnerability of Compartmentalization
}

\author{
Virgil Zeigler-Hill \\ University of Southern Mississippi \\ Carolin J. Showers \\ University of Oklahoma
}

The present studies examined the association between self-concept structure and stability of self-esteem. In two daily diary studies, evaluative integration (organizing positively and negatively valenced self-beliefs into the same self-aspects) was associated with more stable selfesteem than evaluative compartmentalization (organizing positively and negatively valenced self-beliefs into separate self-aspects) among individuals with generally high self-esteem. Moreover, analyses of self-esteem reactivity confirmed that the sensitivity of state self-esteem to daily events was greater for compartmentalized individuals than for individuals with relatively integrative self-concept structures. Compartmentalization also was associated with greater sensitivity to experiences of social rejection in the laboratory, consistent with the view that integration affords greater stability of self-evaluations. These results suggest that some of the benefits believed to be associated with compartmentalization (such as high self-esteem) may have hidden costs that have not previously been considered.

Keywords: compartmentalization; evaluative organization; self; self-concept; self-esteem; self-esteem stability

Cocial psychological approaches to the self have tradi$\checkmark$ tionally focused on self-esteem as a unidimensional index of self-concept (e.g., Rosenberg, 1965). However, recent approaches to the self have taken a more complex and multifaceted view (e.g., Markus \& Wurf, 1987). For example, research on structural features of the self has emphasized that it is not just the content of self-beliefs that matters for an individual's functioning but also moderating features of self-organization such as compartmentalization and integration (Showers, 1992), self-concept clarity (Campbell, 1990), or differential importance (Pelham \& Swann, 1989). Another recent set of approaches to the self highlights the possibility that some individuals who appear to hold very positive self-views actually have quite fragile selves. This idea emerges, for instance, from work on the strategy of selfhandicapping (Berglas \& Jones, 1978) or the narcissistic personality (e.g., Morf \& Rhodewalt, 2001).

The present studies examine possible associations between self-structure and self-esteem stability. Just as research on structural features of the self moved models of the self-concept away from primarily emphasizing content, a focus on self-structure also may help to explain the issues of stability and resilience (Showers \& Zeigler-Hill, 2003). If structural features of the self can moderate the impact of negative content in the selfconcept, they may act as buffers for daily life events,

Authors' Note: Portions of this research are taken from the first author's doctoral dissertation. The data were collected at the University of Oklahoma under the supervision of the second author. Correspondence concerning this article should be addressed to Virgil Zeigler-Hill, Department of Psychology, University of Southern Mississippi, Hattiesburg, MS 39406; e-mail: virgil@usm.edu.

Editor's Note: Dr. James A. Shepperd served as guest action editor for this article.

PSPB, Vol. 33 No. 2, February 2007 143-159

DOI: $10.1177 / 0146167206294872$

(C) 2007 by the Society for Personality and Social Psychology, Inc. 
thereby stabilizing self-esteem. In particular, the compartmentalization model of self-structure makes clear predictions for day-to-day stability in response to life events, even though previous research has emphasized global correlations between self-concept structure and self-esteem or mood (e.g., Showers, 1992, 1995).

\section{Self-Esteem Stability}

Although the vast majority of self-esteem research has focused on level of self-esteem (i.e., relatively enduring favorable or unfavorable attitudes toward the self), it has not gone unrecognized that self-esteem may change over time. The term self-esteem instability describes short-term fluctuations in self-esteem, often conceptualized as the magnitude of change in state self-esteem over time (Kernis, Grannemann, \& Barclay, 1989). The tendency to experience these short-term fluctuations in self-esteem has been described as a dispositional characteristic that interacts with the immediate environment to produce a specific pattern of fluctuations (Kernis, 2003). Previous research has found that individuals with unstable high self-esteem are characterized by anger and hostility (Kernis et al., 1989), engagement in self-protective and self-enhancing strategies (Kernis, Cornell, Sun, Berry, \& Harlow, 1993; Newman \& Wadas, 1997), and responsivity to success and failure (Kernis, Greenier, Herlocker, Whisenhunt, \& Abend, 1997).

\section{Self-Structure: Evaluative Compartmentalization and Integration}

The model of evaluative self-organization focuses on the distribution of positive and negative beliefs across multiple self-aspects (Showers, 1992, 2000). Although individuals typically have self-concepts that are mostly positive (e.g., Schwartz \& Garamoni, 1986), most individuals have at least some important negative beliefs about the self. Among the models of self-concept structure, evaluative organization is unique in that it accounts for both the category structure of specific self-beliefs and the valence of those beliefs (Showers \& Zeigler-Hill, 2003).

The model of evaluative organization identifies two types of self-structure: evaluatively compartmentalized and evaluatively integrative. In compartmentalized selfconcepts, positive and negative attributes or beliefs are separated into distinct self-aspects such that each selfaspect contains primarily positive or primarily negative information about the self. For example, a compartmentalized individual may describe the married self as devoted, warm, caring, and supportive but may use lazy, uncoordinated, selfish, and irritable to describe the basketball player self. In contrast to compartmentalized self-concepts, the self-aspects of integrative self-structures contain a mixture of positive and negative self-beliefs. For example, an integratively organized individual may describe the school teacher self as humorous, forgetful, creative, and disorganized. These two types of selfconcepts are typically assessed on a continuum from relatively integrative to relatively compartmentalized.

The basic model of evaluative organization predicts that for individuals who perceive their positive self-aspects to be relatively important, compartmentalization will be associated with higher self-esteem and more positive mood than will integration (Showers, 1992, 2000). These individuals are said to be positively compartmentalized. They are expected to have positive mood and high selfesteem because their negative self-beliefs have been relegated to relatively unimportant self-aspects that are rarely activated and, therefore, their accessibility is low. However, if a compartmentalized individual's negative selfaspects or attributes are perceived to be important (i.e., negative compartmentalization), negative self-beliefs will be very accessible, resulting in negative mood and low self-esteem. When negative self-beliefs are relatively important, individuals with integrative self-concept structures may more easily maintain positive mood and self-esteem because their self-structure maintains access to both positive and negative self-beliefs, thereby minimizing the impact of those negative self-beliefs that are otherwise unavoidable. Such individuals would be identified as negative integrative (because negative self-beliefs are important); positive integrative structures would be those that are integrative despite many important positive beliefs.

To summarize the basic model of evaluative organization, when the self-concept is basically positive (i.e., positive attributes or aspects are most important or salient), compartmentalized structures should be associated with higher self-esteem and more positive mood than integrative structures. However, when negative aspects or attributes are important, compartmentalized structures should be associated with lower self-esteem and more negative mood than integrative structures. These predictions have been supported by results from a variety of studies showing that the organization of self-beliefs-as measured by a variety of self-descriptive tasks-is associated with an individual's current level of mood or self-esteem (e.g., Rhodewalt, Madrian, \& Cheney, 1998; Showers, 1992; Showers, Abramson, \& Hogan, 1998).

Although these structures are stable enough to predict mood effects at least 1 week later (e.g., Showers \& Kling, 1996), the dynamic model of self-organization suggests that these structures can change, especially in response to life events that may affect the salience of positive or negative beliefs (Showers, 2002). For example, compartmentalized individuals may experience life events that shift the relative importance of their positive and negative selfaspects (so that they shift from positive compartmentalization to negative compartmentalization, or vice versa). 
Moreover, the dynamic model hypothesizes that individuals may shift from compartmentalization to integration, either temporarily to handle acute stress or permanently to handle chronic stress (cf. Showers \& Zeigler-Hill, in press; Showers, Zeigler-Hill, \& Limke, 2006). The present studies have 1- to 2 -week time frames and so they treat evaluative organization at Time 1 as a predictor without assuming that this structure is stable.

\section{Vulnerability of Compartmentalized Self-Concept Structures}

Although the basic model predicts that compartmentalized individuals will have either especially high selfesteem (positively compartmentalized) or especially low self-esteem (negatively compartmentalized), it also implies that high and low self-esteem may be observed in alternation within compartmentalized individuals. This is because compartmentalized self-structures may be vulnerable to shifts in the salience of positive and negative selfaspects, depending on their activation by recent events. Thus, even though a person with a positively compartmentalized self-structure typically feels quite good, a negative experience may activate a purely negative self-aspect, flooding the individual with an unfamiliar set of negative attributes and causing a dramatic shift in state self-esteem. Similarly, individuals who are typically negatively compartmentalized may experience extremely positive feelings about the self when a positive event activates a rarely experienced self-aspect. This vulnerability to shifts in the salience of particular self-aspects should result in compartmentalized individuals experiencing both higher highs and lower lows than individuals with integrative selfconcept structures, which may be observed as fluctuations in state self-esteem (i.e., self-esteem instability).

In contrast, the self-evaluations of individuals with integrative self-concept structures should show less variation in response to the activation of specific selfaspects. Thus, integration should buffer responses to daily events, minimizing fluctuations in state self-esteem. Although the moderate levels of self-esteem associated with integrative structures often have been considered to be a cost of integration (e.g., Showers, Limke, \& Zeigler-Hill, 2004), there may be benefits to having selfesteem that is moderate but stable.

Findings from three different studies are consistent with the notion that compartmentalized structures may be vulnerable to shifts in the salience of particular selfaspects. First, Showers and Kling (1996) found that both positively and negatively compartmentalized individuals took longer than integrative individuals to recover from a sad mood induction if given the opportunity to reflect on their self-beliefs. Presumably, the mood induction activated negative self-aspects in even those individuals with positively compartmentalized self-concepts, creating a flood of negative attributes that made it difficult to restore their premanipulation mood.

Second, although Showers and Kevlyn (1999) found that positively compartmentalized partner structures were associated with positive attitudes toward a partner in the short term, a 1-year follow-up found that compartmentalization was associated with a greater likelihood of relationship dissolution than was integration (among individuals who initially described their partners in relatively positive terms; Showers \& ZeiglerHill, 2004; see Murray \& Holmes, 1999, for similar results). Whereas compartmentalization may help individuals ignore a partner's negative attributes, integration may encourage them to acknowledge, accept, and even resolve the partner's flaws. In contrast, compartmentalization may artificially enhance feelings for a partner in a way that is extremely vulnerable to challenge. Just as compartmentalized partner structures seem to be associated with unstable relationships (as evidenced by higher rates of breakup), it seems likely that a compartmentalized self-concept would be associated with unstable feelings of self-worth.

Third, in Rhodewalt et al.'s (1998) daily diary studies, compartmentalization was correlated with unstable selfesteem. This effect was stronger for more narcissistic individuals, such that compartmentalized narcissists exhibited the most unstable self-esteem. The authors suggest that narcissism may exaggerate emotional responses to the exclusively positive or negative self-knowledge activated within compartmentalized self-aspects. The present studies replicate and extend the main effect of compartmentalization in this paradigm.

\section{Overview and Predictions}

The present studies had two primary goals. The first goal was to examine whether evaluative organization is associated with stability of self-esteem. The prediction was that the self-esteem of individuals with compartmentalized self-concept structures would be less stable than that of integrative individuals. To assess directly the extreme self-esteem responses described above as a vulnerability of compartmentalization, daily assessments of state selfesteem were obtained. However, the compartmentalization model also specifies that these fluctuations in self-esteem should occur in response to events that activate positive or negative self-aspects. Thus, the second goal of these studies was to examine the process hypothesized to contribute to self-esteem instability, namely, the sensitivity of an individual's state self-esteem to daily events. This goal was operationalized in two ways. First, for the daily diary studies, hierarchical linear models were used to conduct daily events analyses, testing whether daily self-esteem fluctuations are significantly associated with daily events (and moderated by compartmentalized 
self-structure). Second, a laboratory manipulation of social acceptance or rejection was used to test whether the state self-esteem of compartmentalized individuals was especially responsive to a positive or negative event under controlled laboratory conditions.

\section{STUDY 1}

To examine the association between evaluative organization and self-esteem stability, measures of self-concept content, self-concept structure, and trait self-esteem were collected in the laboratory. In addition, participants completed daily measures of state self-esteem. It was predicted that relative to integrative individuals, compartmentalized individuals should show less stability on the daily measures of state self-esteem, presumably because of their stronger reactions to daily events. However, the stability measure does not directly assess the covariation between state self-esteem and environmental events. To examine whether the state self-esteem of compartmentalized individuals was more reactive to daily events than the state self-esteem of integrative individuals, follow-up analyses tested whether evaluative organization moderated the association between daily events and daily measures of state self-esteem.

\section{Method}

\section{Participants}

Data from two samples were combined because of the similarity in procedures and measures. Sample A comprised 127 undergraduate students ( 40 men, 87 women) enrolled in introductory psychology in the spring semester who participated in return for partial fulfillment of a research participation requirement. The mean age of participants was 19.03 years $(S D=1.69)$. The racial/ethnic composition was $73 \%$ White, $8 \%$ Black, $5 \%$ Asian, 3\% Native American, 2\% Hispanic, and 9\% Other.

Sample B comprised 153 undergraduate students (50 men, 103 women) enrolled in introductory psychology in the fall semester, who participated in return for partial fulfillment of a research participation requirement. The mean age of participants was 19.03 years $(S D=$ 2.07). The racial/ethnic composition was $80 \%$ White, 5\% Black, 4\% Asian, 4\% Native American, 5\% Hispanic, and $2 \%$ Other.

\section{Measures}

\section{Self-Descriptive Card-Sorting Task}

The content and structure of the self-concept was measured by the card-sorting task used by Showers
(1992; Showers \& Kling, 1996). This card-sorting task is based on the task originally developed by Zajonc (1960) and extended by Linville (1985, 1987). For this task, participants were provided with a deck of 40 cards, each containing a potentially self-descriptive attribute. The deck contained 20 positive (e.g., outgoing, successful, mature, hardworking) and 20 negative attributes (e.g., unloved, isolated, tense, irritable). Participants were given the following initial instructions, "Your task is to think of the different aspects of yourself or your life and then sort the cards into groups where each group describes an aspect of yourself or your life." The remainder of the instructions was very similar to those reported by Showers and Kevlyn (1999). Participants were able to form as many groups as needed, with as many or as few attributes as desired in each group. Attributes could be used in more than one group, and attributes that the respondent did not believe were self-descriptive did not have to be used. Table 1 presents sample card sorts from two participants in this study. After completing the card-sorting task, participants indicated the positivity, negativity, and importance of each self-aspect generated during the card-sorting task using 7-point scales.

Evaluative organization (phi). The measure of evaluative organization is a phi coefficient (Cramer, 1945/ 1974; Everitt, 1977) based on a chi-square statistic. Phi is an index of the deviation from chance of the number of positive and negative attributes in each self-aspect, where chance is the proportion of positive and negative attributes across all self-aspects. The expected frequencies represent chance values for organizing positive and negative attributes without regard for their valence. For example, if the entire card sort contained $30 \%$ negative attributes, then a self-aspect containing 10 attributes would be expected to consist of approximately 7 positive attributes and 3 negative attributes. The observed frequencies are obtained from the card sort. The chisquare statistic computed using these expected and observed frequencies is normalized by dividing by the number of attributes in the sort $(N)$ :

$$
\phi=\sqrt{\frac{\chi^{2}}{N}}
$$

Phi can range from 0 (perfect integration; positive and negative attributes are evenly distributed across all selfaspects) to 1 (perfect compartmentalization; each selfaspect is either purely positive or purely negative). Phi was only computed if two or more negative attributes were included in the card sort. This measure does not depend on the number of self-aspects generated or the 
TABLE 1: Examples of Actual Card Sorts Illustrating Compartmentalization and Integration

\begin{tabular}{|c|c|c|c|c|c|c|c|c|c|c|c|}
\hline \multicolumn{12}{|c|}{ Panel A: Compartmentalized Organization } \\
\hline Me at Home & \multicolumn{2}{|c|}{ Me at Work } & Me in Class & \multicolumn{2}{|c|}{ Me in Norman, OK } & \multicolumn{2}{|c|}{ Me and My Sorority } & \multicolumn{2}{|c|}{$\begin{array}{l}\text { Me With People } \\
\text { I Don't Know }\end{array}$} & \multicolumn{2}{|c|}{$\begin{array}{c}\text { Me When } \\
\text { I'm Stressed }\end{array}$} \\
\hline $\begin{array}{l}\text { Giving } \\
\text { Confident } \\
\text { Comfortable } \\
\text { Lovable } \\
\text { Outgoing } \\
\text { Happy } \\
\text { Friendly } \\
\text { Optimistic }\end{array}$ & \multicolumn{2}{|c|}{$\begin{array}{l}\text { Successful } \\
\text { Capable } \\
\text { Confident } \\
\text { Comfortable } \\
\text { Needed } \\
\text { Communicative } \\
\text { Organized } \\
\text { Interested } \\
\text { Outgoing } \\
\text { Hardworking } \\
\text { Happy } \\
\text { Friendly }\end{array}$} & $\begin{array}{l}\text { Successful } \\
\text { Capable } \\
\text { Independent } \\
\text { Organized } \\
\text { Interested } \\
\text { Hardworking }\end{array}$ & \multicolumn{2}{|l|}{$\begin{array}{l}\text { Successful } \\
\text { Confident } \\
\text { Comfortable } \\
\text { Independent } \\
\text { Fun and enter } \\
\text { Interested } \\
\text { Outgoing } \\
\text { Hardworking } \\
\text { Happy } \\
\text { Friendly } \\
\text { Optimistic }\end{array}$} & \multicolumn{2}{|l|}{$\begin{array}{l}\text { Successful } \\
\text { Giving } \\
\text { Confident } \\
\text { Comfortab } \\
\text { Lovable } \\
\text { Fun and en } \\
\text { Interested } \\
\text { Outgoing } \\
\text { Energetic } \\
\text { Happy } \\
\text { Friendly }\end{array}$} & $\begin{array}{l}\text { - Weary } \\
\text { - Inferior } \\
\text { - Tense }\end{array}$ & & \multicolumn{2}{|c|}{$\begin{array}{l}\text { - Hopeless } \\
\text { - Not the "real n } \\
\text { - Uncomfortable } \\
\text { - Sad and blue } \\
\text { - Irritable } \\
\text { - Disorganized } \\
\text { - Tense }\end{array}$} \\
\hline \multicolumn{12}{|c|}{ Panel B: Integrative Organization } \\
\hline Family & & Religion & Student & $\begin{array}{l}\text { African } \\
\text { American }\end{array}$ & & $\begin{array}{l}\text { imate } \\
\text { ionship }\end{array}$ & Frien & lship & $\begin{array}{l}\text { Drea } \\
\text { las in }\end{array}$ & $\begin{array}{l}m s \\
\text { ioals) }\end{array}$ & Perfectionist \\
\hline $\begin{array}{l}\text { Organized } \\
\text { - Irritable } \\
\text { - Disagreeing } \\
\text { - Self-centered } \\
\text { Communicative } \\
\text { Lovable } \\
\text { Fun and entert } \\
\text { Energetic }\end{array}$ & ining & $\begin{array}{l}\text { Needed } \\
\text { Organized } \\
\text { Giving } \\
\text { Happy } \\
\text { - Irritable } \\
\text { Optimistic }\end{array}$ & $\begin{array}{l}\text { Successful } \\
\text { - Lazy } \\
\text { Mature } \\
\text { - Irritable } \\
\text { Organized } \\
\text { Intelligent } \\
\text { Interested } \\
\text { Hardworking } \\
\text { - Tense }\end{array}$ & $\begin{array}{l}\text { - Hopeless } \\
\text { Organized } \\
\text { Confident } \\
\text { - Irritable }\end{array}$ & $\begin{array}{l}\text { Comfor } \\
\text { - Irrital } \\
\text { - Imma } \\
\text { - Insect } \\
\text { - Inferi } \\
\text { - Tense }\end{array}$ & $\begin{array}{l}\text { able } \\
\text { e } \\
\text { ure } \\
\text { e } \\
\text { r organized }\end{array}$ & $\begin{array}{l}\text { Giving } \\
\text { - Uncomf } \\
\text { - Insecure } \\
\text { - Irritable } \\
\text { - Isolated } \\
\text { Organized } \\
\text { Friendly } \\
\text { - Not the }\end{array}$ & $\begin{array}{l}\text { rtable } \\
\text { "real me" }\end{array}$ & $\begin{array}{l}\text { Indepe } \\
\text { Organi } \\
\text { - Wear }\end{array}$ & $\begin{array}{l}\text { dent } \\
\text { ed }\end{array}$ & $\begin{array}{l}\text { Successful } \\
\text { - Disagreeing } \\
\text { - Irritable } \\
\text { Capable } \\
\text { Confident } \\
\text { Organized } \\
\text { Intelligent } \\
\text { Outgoing } \\
\text { Hardworking } \\
\text { - Tense }\end{array}$ \\
\hline
\end{tabular}

NOTE: Negative attributes are identified by a minus sign. Panel A: compartmentalization $=1.00$, differential importance $=.80$, and proportion of negative attributes $=.17$. Panel B: compartmentalization $=.32$, differential importance $=.65$, and proportion of negative attributes $=.40$.

proportion of positive and negative attributes used. Further detail on the computation of phi is provided by Showers and Kevlyn (1999).

Differential importance. Differential importance is a measure of the relative importance of positive and negative self-aspects (Pelham \& Swann, 1989). Differential importance is the within-subject correlation between participants' ratings of their self-aspects (i.e., positivity ratings - negativity ratings) and the importance assigned to those self-aspects by the participants. Scores can range from -1 to +1 , with positive scores indicating that positive self-aspects are considered more important than negative ones and negative scores indicating that negative self-aspects are considered more important than positive ones (Showers, 1992).

Proportion of negative attributes. The proportion of negative attributes is a measure of self-concept content that is calculated by dividing the number of negative attributes appearing in a respondent's card sort by the total number of attributes used.

\section{Trait Self-Esteem}

Participants completed the Rosenberg Self-Esteem Scale (RSES; Rosenberg, 1965), a well-validated measure of self-esteem (Blaskovich \& Tomaka, 1991). Testretest correlations greater than .80 have been previously reported (Rosenberg, 1965). Participants were instructed to complete the scale according to how they typically or generally feel about themselves. Responses were made on scales ranging from 1 (strongly disagree) to 5 (strongly agree). For the present study, the internal consistency of this measure was high $(\alpha=.85)$.

\section{State Self-Esteem and Aggregate Instability}

To assess state self-esteem, participants completed the RSES with instructions to give the response that best reflected how they felt at the moment they completed the form. Responses were made on scales ranging from 1 (strongly disagree) to 10 (strongly agree). For each participant, the within-subject standard deviation across the repeated assessments of state selfesteem served as an aggregate measure of self-esteem 
instability, with higher standard deviations indicating more unstable self-esteem.

\section{Daily Events}

Participants in Sample A completed the Daily Hassles and Uplifts Scale (DeLongis, Folkman, \& Lazarus, 1988) each evening. This measure consisted of 53 items concerning domains of life that may be sources of either stress or satisfaction (e.g., family, work, health, and money). The response scale for this measure was modified so that participants indicated whether each event occurred and if those events that occurred were either a source of stress (i.e., daily hassle) or satisfaction (i.e., daily uplift). Participants were not asked about the strength or importance of these events. The final score for daily hassles consisted of the number of daily events perceived as stressful; the final score for daily uplifts consisted of the number of daily events perceived as satisfying.

Participants in Sample B recorded their daily events using a modified version of the Daily Events Survey (DES; Butler, Hokanson, \& Flynn, 1994). The DES was employed with Sample B because of a concern that many of the items on the Daily Hassles and Uplifts Scale may not be relevant for the self-esteem of college students (e.g., housework, home repair, yardwork) and, hence, infrequently endorsed. The DES was chosen, in part, because it was specifically constructed for use with college students. Following the modifications used in previous research (e.g., Nezlek \& Gable, 2001), the DES included 22 events (12 positive, 10 negative) equally representing social and achievement domains. Sample events are "was excluded or left out by my group of friends," "fell behind in coursework or duties," and "classmate, teacher, coworker, or friend complimented me on my abilities." In addition, four generic items were created to measure other unspecified events (i.e., positive social event, negative social event, positive achievement event, and negative achievement event). The final score for negative events was the number of negative event items endorsed; the positive events score was the number of positive event items endorsed.

\section{Procedure}

Participants from Sample A completed measures of self-concept content and structure as well as a measure of trait self-esteem in small groups of 2 to 12 participants. These participants were then instructed to complete measures of state self-esteem at 12-hour intervals (at approximately 10 a.m. and 10 p.m.) for 14 consecutive days. These participants also completed the Daily Hassles and Uplifts Scale each evening at approximately 10 p.m. To enhance compliance with these instructions, participants received enough forms for 1 week at the beginning of the study and were instructed to return the completed measures to a designated location every 3 to 4 days. At the end of the 1st week, participants received forms for the 2 nd week and were again instructed to return the completed forms to a designated location every 3 to 4 days.

Participants from Sample B completed measures of self-concept content and structure as well as a measure of trait self-esteem in small groups of 2 to 6 participants. These participants were then instructed to complete a measure of state self-esteem at 24-hour intervals (at approximately 10 p.m. each day) for 7 consecutive days. These participants also completed the DES each evening at approximately 10 p.m. Participants were instructed to return the completed measures to a designated location every 3 to 4 days.

\section{Results}

Of the 127 participants from Sample A who began the study, 6 participants failed to complete the card-sorting task or used fewer than two negative attributes. In addition, data from 12 participants who completed daily measures for fewer than 10 (out of 14) days were excluded. Analyses were conducted using the 109 remaining participants. On average, these participants completed 12.54 $(S D=1.08)$ daily measures (i.e., state self-esteem) in the morning and $13.24(S D=0.93)$ daily measures (i.e., state self-esteem and daily events) in the evening.

Of the 153 participants from Sample B who began the study, 10 participants failed to complete the card-sorting task or used fewer than two negative attributes and 5 participants failed to complete measures relevant to the current study. In addition, data from an additional 20 participants who completed daily measures for fewer than 5 (out of 7) days were excluded. Analyses were conducted for the 118 remaining participants. On average, these participants completed $6.25(S D=0.43)$ daily measures (i.e., state self-esteem and daily events) in the evening.

In the present analyses, the combined sample $(N=$ 227 ) is used whenever possible.

\section{Descriptive Statistics}

Table 2 presents the means, standard deviations, and intercorrelations for the measures used in the present study. On average, the participants' card sorts consisted of 6.4 self-aspects and contained 8.0 attributes per selfaspect. The card sorts contained an average of 13.9 $(28 \%)$ negative attributes. As indicated in Table 2, proportion of negative attributes was arcsine transformed to reduce skew (Cohen, Cohen, West, \& Aiken, 2003). Note that compartmentalization is positively correlated with proportion of negative attributes. This is typical in our studies and may occur because it is easy to include 
TABLE 2: Intercorrelations and Descriptive Statistics

\begin{tabular}{lccccc}
\hline Variable & 1 & 2 & 3 & 4 & 5 \\
\hline $\begin{array}{l}\text { 1. Evaluative } \\
\text { Organization }\end{array}$ & - & .10 & $.35^{* * *}$ & -.14 & .18 \\
$\begin{array}{l}\text { 2. Differential } \\
\text { importance }\end{array}$ & .14 & - & $-.21^{*}$ & $.24 *$ & -.04 \\
$\begin{array}{l}\text { 3. Proportion } \\
\text { of negative }\end{array}$ & $.53 * * *$ & -.07 & - & $-.33^{* * *}$ & .16 \\
$\quad$ attributes & & & & & \\
4. Trait self-esteem & -.17 & $.38^{* * *}$ & $-.47^{* * *}$ & - & -.13 \\
5. Self-esteem & $.25 *$ & -.09 & $.38^{* * *}$ & $-.29 * *$ & - \\
$\quad$ instability & & & & & \\
M Sample A & .71 & .47 & .29 & 42.51 & 6.46 \\
SD Sample A & .24 & .45 & .15 & 5.30 & 4.51 \\
M Sample B & .69 & .41 & .30 & 42.32 & 4.97 \\
SD Sample B & .22 & .49 & .14 & 5.31 & 3.78 \\
\hline
\end{tabular}

NOTE: Correlations for Sample A $(N=109)$ are presented above the diagonal, whereas correlations for Sample B $(N=118)$ are presented below the diagonal. Proportion of negative attributes is arcsine transformed (actual values: Sample A, $M=0.28, S D=0.14$; Sample B, $M=$ $0.29, S D=0.13)$.

$* p<.05 . * p<.01 . * * p<.001$.

many negative attributes in a compartmentalized structure (e.g., me before exams) with little impact on selfesteem. In previous work, the predicted association of positive compartmentalization and high self-esteem is seen when the proportion of negative attributes is held constant (e.g., Showers, 1992).

Participants who had been excluded for failure to provide all measures did not differ from those retained on the first four measures listed in Table 2, Sample A: $|t| s<.85$, $n s$; Sample B: $|t| s<.79$, ns. Moreover, the number of days participants contributed data was not correlated with any of these measures or with aggregate self-esteem instability, Sample A: $|r| s<.13, n s$; Sample B: $|r| s<.17, n s .{ }^{1}$

\section{Aggregate Instability Analysis}

The present analysis examined the association between evaluative organization and self-esteem instability by regressing the aggregate measure of self-esteem instability (the standard deviation of each individual's daily state self-esteem scores) onto the following measures: evaluative organization, differential importance, proportion of negative attributes, trait self-esteem, and sample (A or B). Although we predicted a main effect association between evaluative organization and instability, preliminary analyses included differential importance and proportion of negative attributes as predictors because of their critical role in previous research predicting current mood and self-esteem (e.g., Showers, 1992). Here, trait self-esteem is included as a predictor because of its association with the criterion variable, self-esteem instability (see Table 2). Interactions involving main effect terms were included for exploratory purposes. All continuous predictor variables were centered for the purpose of testing interactions (Aiken \& West, 1991).

Preliminary results showed no significant interactions involving differential importance and proportion of negative attributes, so these terms were trimmed. In the final analysis, the main effect terms for evaluative organization, differential importance, proportion of negative attributes, trait self-esteem, and sample were entered on Step 1. On Step 2, all two-way interactions were entered for evaluative organization, trait self-esteem, and sample. On Step 3, the three-way interaction of evaluative organization, trait self-esteem, and sample was entered.

Two significant main effects emerged from this analysis. There was an association between proportion of negative attributes and self-esteem instability such that people who used more negative attributes were more unstable, $\beta=.15, p<.05$ (cf. Kernis \& Waschull, 1995). There also was an association between sample and selfesteem instability, such that Sample A reported higher levels of instability than Sample B, $\beta=-.18, p<.01 .^{2}$ The main effect of evaluative organization was marginally significant, $\beta=.14, p<.06$, such that individuals with compartmentalized self-structures reported less stable self-esteem. This marginal main effect was qualified by a significant interaction of evaluative organization and trait self-esteem on Step 2, $\beta=.14, p<.03$. Predicted values for this interaction are shown in Figure 1. To examine the patterns of this interaction, simple slopes tests were employed (Aiken \& West, 1991). These analyses showed that for individuals with low trait self-esteem, state self-esteem was relatively unstable regardless of whether they possessed compartmentalized or integrative self-concept structures, $\beta=-.07$, ns. However, among individuals with high trait self-esteem, integrative individuals showed greater stability of state self-esteem than did compartmentalized individuals, $\beta=.24, p<.02$.

\section{Daily Events Analyses}

Whereas the previous analyses examined an aggregate measure of self-esteem instability (i.e., fluctuations in state self-esteem over time), the present analyses test directly the link between daily state self-esteem and the positive and negative events reported each day. The daily diary data from the present study comprised a multilevel data structure because observations at one level of analysis (i.e., days) were nested within another level of analysis (i.e., individuals). Due to the hierarchical structure of the data, a series of multilevel random coefficient models (MRCMs) using the program HLM (Bryk, Raudenbush, \& Congdon, 1998) were employed in the present study. MRCM conceptually involves two steps. First, a regression equation is estimated for each individual at Level 1 (the within-person level), which yields intercept and slope 


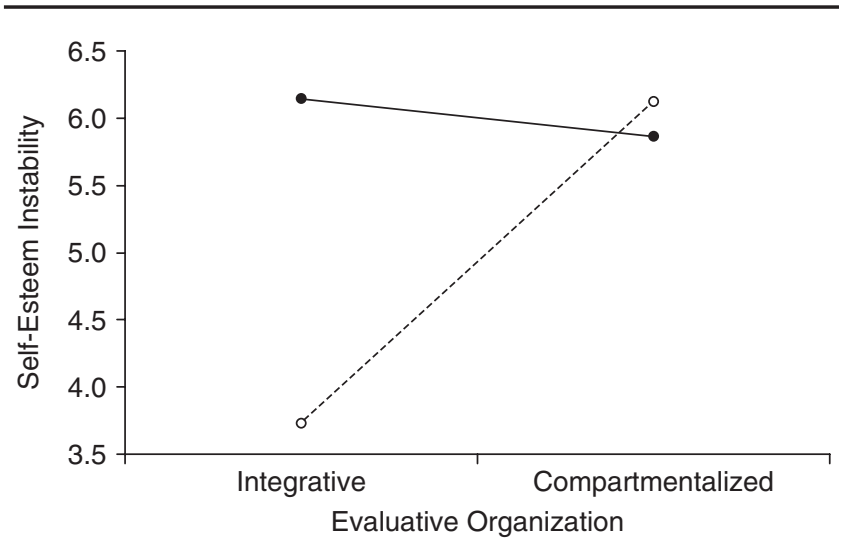

$\rightarrow-$ Low Self-Esteem --o-. High Self-Esteem

Figure 1 Predicted values for self-esteem instability, illustrating the interaction of evaluative organization and trait self-esteem at values that are 1 standard deviation above and below the means.

coefficients to index the association between variables at the daily level (e.g., "Does self-esteem tend to decrease on days when negative events occur?"). Second, Level 2 (the between-persons level) examines whether the regression slopes obtained from the within-person level differ across individuals, depending on the level of an individualdifference variable (e.g., "Is the tendency to experience lower self-esteem on days when negative events occur especially strong for individuals with compartmentalized self-concept structures?”).

The measures of daily events differed between Sample A (Daily Hassles and Uplifts Scale) and Sample B (DES). Because we could not assume that the means and standard deviations of positive and negative events for these two samples were equivalent, the daily events analyses for Samples A and B were conducted separately. Because the DES events measure is likely a more appropriate measure of both positive and negative events experienced by college students, we first report detailed results for Sample B and then provide a brief summary of the results for Sample A.

\section{Descriptive Statistics for Measures of State Self-Esteem and Daily Events}

Descriptive statistics for the daily measures for Samples A and B are provided in Table 3. These descriptive statistics were obtained by an unconditional model (i.e., contains no terms other than intercepts at any level) for each daily measure. The Level 1 and Level 2 equations were as follows:

Level 1 (within-person): $\mathrm{y}_{\mathrm{ij}}=\beta_{0 \mathrm{j}}+\mathrm{r}_{\mathrm{ij}}$; Level 2 (between-persons): $\beta_{0 \mathrm{j}}=\gamma_{00}+\mathrm{u}_{0 \mathrm{j}}$.
TABLE 3: Descriptive Statistics for State Self-Esteem and Daily Events

\begin{tabular}{lrrrr}
\hline & & $\begin{array}{c}\text { Within- } \\
\text { Person SD }\end{array}$ & $\begin{array}{c}\text { Between- } \\
\text { Person SD }\end{array}$ & Reliability \\
\hline Sample A & & & & \\
$\quad$ State self-esteem & 81.58 & 7.75 & 13.27 & .97 \\
$\quad$ Daily hassles & 2.57 & .83 & 1.08 & .96 \\
$\quad$ Daily uplifts & 3.48 & .65 & 1.03 & .97 \\
Sample B & & & & \\
$\quad$ State self-esteem & 80.06 & 6.03 & 11.61 & .96 \\
$\quad$ Negative daily events & 7.00 & 2.05 & 2.96 & .95 \\
$\quad$ Positive daily events & 3.73 & 1.70 & 2.74 & .94 \\
\hline NOTE: $N_{\text {Sample A }}=109 ; N_{\text {Sample B }}=118$. & &
\end{tabular}

In this Level 1 model, $y_{i j}$ is a measure of state self-esteem or daily events for person $j$ on day $i, \beta_{0 j}$ is a random coefficient representing the mean for person $j$ (across the $\mathrm{i}$ days for which each person provided data), $\mathrm{r}_{\mathrm{ij}}$ represents the error associated with each measure, and the variance of $r_{i j}$ constitutes the within-person error variance. In this Level 2 model, $\gamma_{00}$ represents the grand mean of the person-level means from the within-person model, $\mathrm{u}_{0 \mathrm{j}}$ represents the error of $\beta_{0 \mathrm{j}}$, and the variance of $\mathrm{u}_{0 \mathrm{j}}$ constitutes the between-person error variance. Each of the daily measures had a reliability coefficient of .94 or greater (see Table 3 ).

\section{Evaluative Organization and Average Daily Events or Average State Self-Esteem}

A two-level MRCM was used to examine the association of evaluative organization with state self-esteem and daily events. These effects are examined at Level 2 by modeling the variability of $\beta_{0 ;}$, the coefficient from the Level 1 model representing the person mean. This analysis is referred to as a "means as outcomes" analysis (Bryk \& Raudenbush, 1992). The Level 2 model shown below was used to examine whether evaluative organization, differential importance, proportion of negative attributes, or trait self-esteem were associated with average levels of daily events or state self-esteem (averaged across all daily reports). (Terms for the twoway interactions of the predictors were trimmed from the model because they did not approach significance, $|B s|<.18, n s$. $)$

$$
\begin{aligned}
\beta_{0 \mathrm{j}}=\gamma_{00} & +\gamma_{01}(\mathrm{PHI})+\gamma_{02}(\mathrm{DI})+\gamma_{03}(\mathrm{NEG}) \\
& +\gamma_{04}(\mathrm{RSES})+\mathrm{u}_{0 \mathrm{j}} \cdot
\end{aligned}
$$

For average state self-esteem, the only significant association that emerged was an association with trait selfesteem, $B=8.91, p<.001$, such that individuals who report higher levels of trait self-esteem also tend to report relatively high levels of state self-esteem. No 
other associations emerged from these analyses. That is, the measures of self-concept structure were not associated with individuals' average level of state self-esteem or average number of daily events.

\section{Daily Events and State Self-Esteem}

A two-level MRCM was used to examine withinperson relationships between daily events and daily state self-esteem. For these analyses, daily measures of positive events and negative events were person-mean centered (Raudenbush \& Bryk, 2002). This technique eliminates the influence of habituation to the average number of positive and negative daily events in their lives (as well as possible self-report biases) and predicts changes in state self-esteem in response to deviations from the person's average number of events.

The Level 1 model was as follows:

$$
\begin{aligned}
\mathrm{y}_{\mathrm{ij}}=\beta_{0 \mathrm{j}} & +\beta_{1 \mathrm{j}}(\text { POSITIVE EVENTS }) \\
& +\beta_{2 \mathrm{j}}(\text { NEGATIVE EVENTS })+\mathrm{r}_{\mathrm{ij}},
\end{aligned}
$$

in which y is the state self-esteem of person $j$ on day $i$, $\beta_{0 \mathrm{j}}$ is a random coefficient representing the intercept for person $\mathrm{j}, \beta_{1 \mathrm{j}}$ is a random coefficient for positive events, $\beta_{2 j}$ is a random coefficient for negative events, and $r_{i j}$ represents error. Positive and negative daily events were entered together to differentiate their impact on daily state self-esteem. Within-person relationships between daily events and daily state self-esteem were examined by analyzing Level 1 (within-person) coefficients at Level 2 (between-persons) using the following model:

Intercept: $\beta_{0 \mathrm{j}}=\gamma_{00}+\mathrm{u}_{0 \mathrm{j}}$;

Positive Events: $\beta_{1 \mathrm{j}}=\gamma_{10}+\mathrm{u}_{1 \mathrm{j}}$;

Negative Events: $\beta_{2 \mathrm{j}}=\gamma_{20}+\mathrm{u}_{2 \mathrm{j}}$.

In this model, $\gamma_{00}$ represented the average of the withinperson intercepts, whereas $\gamma_{10}$ and $\gamma_{20}$ represented the average of the positive events and negative events slopes, respectively. All three within-person coefficients were modeled as random (i.e., $\mathrm{u}_{0 \mathrm{j}}, \mathrm{u}_{1 \mathrm{j}}$, and $\mathrm{u}_{2 \mathrm{j}}$ terms are included). As expected, both positive daily events $(B=$ $0.51, p<.001)$ and negative daily events $(B=-0.41$, $p<0.01)$ were associated with daily state self-esteem. Across all participants, state self-esteem was higher on days with high numbers of positive events or low numbers of negative events.

\section{Evaluative Organization as a Moderator of Within-Person Relationships Between Daily Events and Daily State Self-Esteem}

This analysis examined how individual differences in evaluative organization moderated the association between daily state self-esteem and daily events after controlling for differential importance, proportion of negative attributes, and trait self-esteem. These analyses elaborate on the marginal main effect for evaluative organization found in the self-esteem instability analysis. To determine whether the within-person relationships described in the previous analyses varied as a function of individual differences in evaluative organization, coefficients from Level 1 were analyzed at Level 2 using the following model:

$\beta_{0 \mathrm{j}}=\gamma_{00}+\gamma_{01}(\mathrm{PHI})+\gamma_{02}(\mathrm{DI})+\gamma_{03}(\mathrm{NEG})+\gamma_{04}(\mathrm{RSES})+\mathrm{u}_{0 \mathrm{j}}$; $\beta_{1 \mathrm{j}}=\gamma_{10}+\gamma_{11}(\mathrm{PHI})+\gamma_{12}(\mathrm{DI})+\gamma_{13}(\mathrm{NEG})+\gamma_{14}(\mathrm{RSES})+\mathrm{u}_{1 \mathrm{j}}$; $\beta_{2 j}=\gamma_{20}+\gamma_{21}(\mathrm{PHI})+\gamma_{22}(\mathrm{DI})+\gamma_{23}(\mathrm{NEG})+\gamma_{24}(\mathrm{RSES})+\mathrm{u}_{2 \mathrm{j}}$.

In these models, the moderating effect of evaluative organization was tested by the significance of the $\gamma_{11}$ and $\gamma_{21}$ coefficients (for positive events and negative events, respectively). These coefficients may be interpreted like standardized regression coefficients because Level 2 variables were standardized prior to analysis (Nezlek \& Plesko, 2003). The results of these analyses are summarized in Table 4. Evaluative organization moderated the association of daily state self-esteem with positive daily events, $B=0.27, p<.05$, and negative daily events, $B=-0.25, p<.05$. It is important to note that these cross-level interactions are unique effects. That is, the interaction of evaluative organization and positive daily events emerges even when the effect of negative daily events on daily state self-esteem is controlled. The predicted values for these cross-level interactions are shown in Figure 2. To examine the patterns of these cross-level interactions, simple slopes tests were employed that have been adapted for multilevel models (Curran, Bauer, \& Willoughby, 2006). These analyses showed that individuals with compartmentalized self-concept structures experienced a significant increase in daily state self-esteem on days with relatively high numbers of positive events, $B=0.74, p<.001$, as well as a significant decrease in daily state self-esteem as their number of negative events increased, $B=-0.59, p<.001$. Individuals with an integrative self-concept structure did not experience a significant change in their daily state self-esteem as the number of positive events, $B=$ $0.21, n s$, or negative events increased, $B=-0.10$, ns. Taken together, these results suggest that the daily state self-esteem of compartmentalized individuals is more closely associated with daily events than is the daily state self-esteem of integrative individuals.

\section{Sample A: Summary of Daily Events Analyses}

The results of the daily events analyses for Sample A were very similar to those for Sample B with regard to 
TABLE 4: MRCM Analysis: Evaluative Organization as a Moderator of Within-Person Relationships Between Daily State Self-Esteem and Daily Events

\begin{tabular}{|c|c|c|c|c|c|c|c|c|c|c|c|c|}
\hline & \multicolumn{4}{|c|}{ Intercept } & \multicolumn{4}{|c|}{ Positive Events } & \multicolumn{4}{|c|}{ Negative Events } \\
\hline & Coeff..$^{a}$ & $\mathrm{SE}$ & $\mathrm{t}$ & Effect Size $e^{b}$ & Coeff..$^{a}$ & $\mathrm{SE}$ & $\mathrm{t}$ & Effect Size $e^{b}$ & Coeff. ${ }^{a}$ & SE & $\mathrm{t}$ & Effect Size $e^{b}$ \\
\hline Intercept & 80.43 & .71 & $113.11 * * *$ & & .48 & .11 & $4.38 * * *$ & -.34 & .14 & $-2.44 \%$ & & \\
\hline Phi & -1.07 & .80 & -1.34 & & .27 & .11 & $2.38 *$ & .22 & -.25 & .13 & $-1.92 *$ & .18 \\
\hline DI & .84 & .81 & 1.03 & & -.15 & .11 & -1.44 & & -.09 & .13 & -.70 & \\
\hline Neg & .51 & .74 & .69 & & -.02 & .09 & -.25 & & .01 & .13 & .07 & \\
\hline RSES & 8.91 & .80 & $11.14 * * *$ & .72 & -.03 & .10 & -.32 & & .17 & .17 & 1.01 & \\
\hline
\end{tabular}

NOTE: $N=118, d f=116$. MRCM = multilevel random coefficient models, $S E=$ standard error; Phi $=$ evaluative organization; $\mathrm{DI}=$ differential importance; Neg = proportion of negative attributes; RSES = Rosenberg Self-Esteem Scale.

a. Unstandardized coefficient.

b. Effect sizes were computed with the following formula (Rosenthal \& Rosnow, 1984) and are presented for significant effects only: $r=$ square root of $\left[t^{2} /\left(t^{2}+d f\right)\right]$.

$* p<.05 . * * p<.001$.

negative events. Although Sample A provided both morning and evening reports of state self-esteem, only the evening reports were used for the daily events analyses. Evaluative organization moderated the association between daily state self-esteem and daily hassles in Sample A, $B=-1.09, p<.01$. Simple slopes tests found that individuals with compartmentalized self-concept structures reported lower state self-esteem on days with relatively high numbers of daily hassles, $B=-2.05, p<$ .001 . Individuals with an integrative self-concept structure did not experience significant declines in daily state self-esteem on days they reported more daily hassles, $B=0.13$, ns. In contrast to the analyses of positive events for Sample B, the results for Sample A did not show evaluative organization as a significant moderator of the relationship between state self-esteem and daily uplifts, $B=0.47$, ns. One possible explanation is that the measure of daily uplifts was not particularly sensitive to the types of positive events that are relevant to the self-esteem of college students.

\section{Discussion}

In the aggregate instability analyses, despite a marginal main effect, the predicted association of compartmentalization and instability of state self-esteem was significant only for individuals with high levels of trait self-esteem. Among individuals with high trait selfesteem, integrative individuals showed greater stability of state self-esteem than did compartmentalized individuals. Individuals with low trait self-esteem tended to be unstable in their state self-esteem regardless of selfstructure. If there are advantages of integration, at least in terms of self-esteem stability, they are found primarily among individuals who possess relatively positive views of the self. It is possible that some threshold level of positivity (e.g., high self-esteem or a high proportion of positive self-beliefs) must be met before integration is able to protect and stabilize self-esteem. Moreover, it would make sense that integrative individuals with relatively negative self-concepts-and accompanying low trait self-esteem-would fail to internalize the stabilizing implications of their integrative thinking because it would not be to their advantage to give up transient good feelings when positive events occurred.

This result suggests that the high level of self-esteem that typically characterizes positively compartmentalized individuals may be difficult for those individuals to sustain and may result in frequent fluctuations in state self-esteem. According to the compartmentalization model, these fluctuations may be due to the short-term activation of self-aspects that are mostly negative. In contrast, a similar negative event may have less impact on the state self-esteem of an individual with an integrative self-concept structure because this individual is able to maintain access to positive self-beliefs.

The hypothesis concerning the reactivity of state selfesteem to daily events was supported by the results of the present study. The state self-esteem of compartmentalized individuals was more responsive to daily events than the state self-esteem of integrative individuals. That is, the state self-esteem of compartmentalized individuals increased more than the state self-esteem of integrative individuals on days with many positive events and decreased more on days with many negative events. Thus, integrative individuals seem to be buffered against the impact of both positive and negative events on self-esteem. ${ }^{3}$

\section{STUDY 2}

The results of Study 1 indicate that the self-esteem of compartmentalized individuals may be more responsive to daily events than is the self-esteem of integrative individuals. However, participants in Study 1 merely 
Panel A

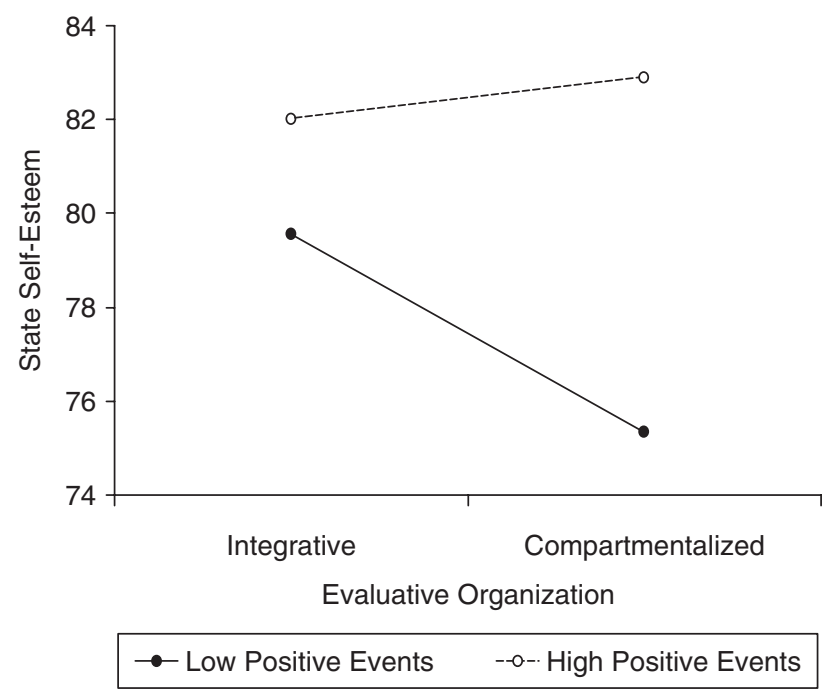

Panel B

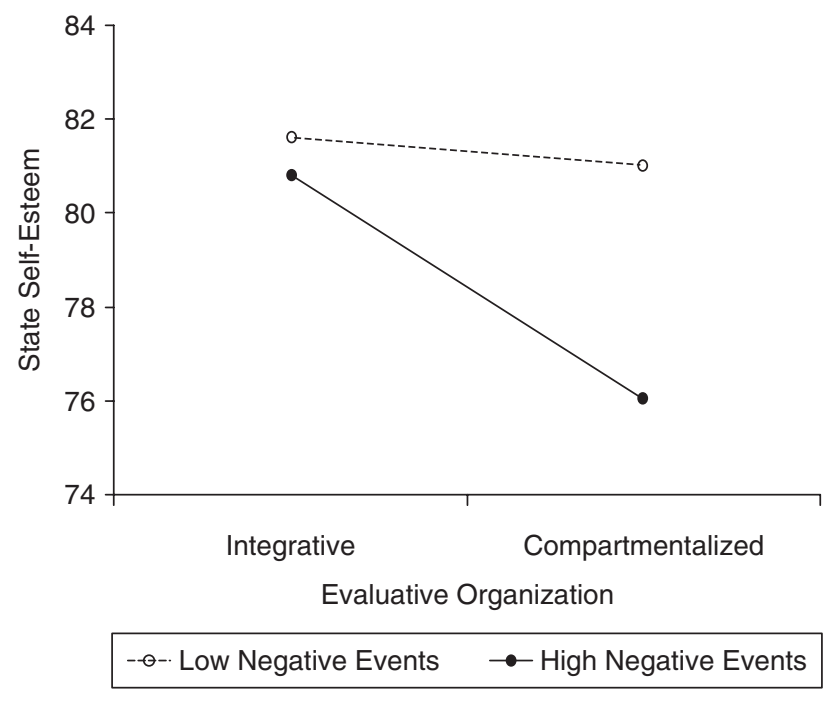

$\overline{\text { Figure } 2}$ Predicted values for daily state self-esteem, illustrating the cross-level interaction of evaluative organization (at values 1 standard deviation above and below the grand mean) with positive events (at values 2 standard errors above and below the group mean, Panel A) and negative events (at values 2 standard errors above and below the group mean, Panel B).

reported the events they experienced in the course of their daily lives. This leaves open the possibility that the daily experiences of compartmentalized and integrative individuals differ in some systematic fashion. For example, the positive and negative events experienced by compartmentalized individuals may in reality have greater implications for self-esteem than the events experienced by integrative individuals. Although the number of positive and negative events experienced was not correlated with compartmentalization, subtle differences in the types of events experienced could explain the reactivity of individuals with compartmentalized self-structures. For this reason, Study 2 was designed to test the causal relationship between the experience of an event and the individual's response. This was accomplished by creating an experience of social acceptance or rejection in the laboratory. The prediction was that the state self-esteem of individuals with compartmentalized self-concepts would be more sensitive to social acceptance and rejection, whereas the state self-esteem of integrative individuals would be less affected by these manipulations. Social experiences seemed appropriate for the present study because of the importance for self-esteem of gaining interpersonal acceptance and forming strong social bonds (Baumeister \& Leary, 1995; Baumeister \& Tice, 1990) and the substantial literature on the impact of social rejection (e.g., Leary, Tambor, Terdal, \& Downs, 1995).

\section{Method}

\section{Participants}

Participants were 138 undergraduates from Sample B in Study 1. This group includes 118 individuals from the analyses for Study 1 as well as 20 individuals who were previously excluded because they did not complete the daily measures. The present analyses focus on data collected during the second laboratory session.

\section{Measures}

In addition to the measures previously reported for Sample B, the second laboratory session included additional measures of state self-esteem and perceived social rejection.

\section{Perceived Social Rejection}

Participants indicated their current level of perceived social rejection by indicating their level of agreement with the statement "At this moment, I feel rejected by others." Responses were made on a scale ranging from 1 (strongly disagree) to 10 (strongly agree).

\section{Procedure}

To increase the impact of social rejection or acceptance, participants were asked to complete a questionnaire during the first laboratory session that would provide selfdescriptive information to 3 participants with whom they believed they would perform a mental visualization task during the second laboratory session. The questionnaire asked for basic personal information such as first name, college major, and hobbies. At the beginning of the second laboratory session (1 week later), participants were given the self-descriptive questionnaires ostensibly belonging to 
their three teammates. They were given $5 \mathrm{~min}$ to read these questionnaires and to begin forming a mental image of their teammates. Participants were then instructed to visualize themselves and their teammates during an online game of virtual ball-toss. This Cyberball task was developed to induce feelings of social rejection and ostracism (Williams, Cheung, \& Choi, 2000).

Each action taken by any member of the team was presented on the screen. When participants received the ball, they chose to whom to throw the ball by selecting that player's name. On each of the turns in which participants were not in possession of the ball, they watched what was occurring between the three computer-generated players whom they believed were other participants in the laboratory session. The computer-generated players' throws were controlled by an algorithm. The probability that they would throw the ball to the participant depended on the condition to which participants were randomly assigned. In the social acceptance condition, participants received the ball during $25 \%$ of 30 trials, which is what would be expected by chance. In the social rejection condition, participants received the ball twice during the initial rounds and then did not receive it during the remainder of the task.

Following this manipulation, participants reported their state self-esteem and perceived social rejection. In an effort to capture the effects of social rejection or acceptance on self-esteem and perceived rejection over time, these ratings were collected at three points in time: immediately following the manipulation (Time 1), 60 min after the manipulation (Time 2), and at 10 p.m. that night (Time 3). Between Time 1 and Time 2, participants completed a questionnaire related to the mental visualization task (e.g., "I was able to visualize the game very well"), a questionnaire asking participants to rate themselves and their teammates on a variety of traits, and 7 personality scales that were not relevant to the present study. Following Time 2, participants were debriefed concerning the purpose of the study. Of importance, this debriefing included a description of the social rejection manipulation. Before leaving the laboratory, participants were asked to complete a final set of ratings at $10 \mathrm{p} . \mathrm{m}$. that night (Time $3)$. Thus, participants were aware of the purpose of the study-and that their Cyberball teammates did not actually exist-when they completed the Time 3 ratings. Participants returned their Time 3 ratings to the laboratory on the next day in exchange for additional credit toward their research participation requirement.

\section{Results}

Of the 138 participants who completed all of the relevant measures for the present study, 63 were randomly assigned to the acceptance condition and 75 were randomly assigned to the rejection condition.

\section{State Self-Esteem and Perceived Rejection Following Social Rejection or Acceptance}

As a manipulation check, the difference in perceived social rejection between the social rejection and social acceptance conditions was examined for Time 1 (immediately following rejection). As expected, participants in the social rejection condition reported greater feelings of rejection $(M=3.31, S D=2.48)$ than did participants in the social acceptance condition $(M=2.43, S D=1.90)$ immediately following the manipulation, $t^{\prime}(134.88)=$ $-2.35, p<.02$.

The association between self-concept structure and reactions to the social rejection manipulation were examined by a series of hierarchical multiple regressions. As in the aggregate instability analyses for Study 1 , all two- and three-way interactions of the variables entered on Step 1 were included in preliminary analyses. Interactions involving differential importance and proportion of negative attributes were included for exploratory purposes but these interactions were trimmed from the final model because they did not approach conventional levels of significance. In the final analysis, Step 1 tested the main effects for evaluative organization, differential importance, proportion of negative attributes, trait self-esteem, and social rejection condition (coded as $0=$ acceptance and $1=$ rejection). On Step 2, the two-way interactions of evaluative organization, trait self-esteem, and social rejection condition were entered. Following the procedures of Aiken and West (1991), all main effect terms were centered before computing the product terms that tested interactions. These analyses were conducted for the measures of state self-esteem and perceived rejection following the manipulation.

\section{Time 1: Immediately Following Social Rejection or Acceptance}

As expected, a significant main effect of trait selfesteem was found such that individuals with high levels of self-esteem continue to report relatively high levels of state self-esteem following the laboratory manipulation, $\beta=.60, p<.001$. A significant main effect of evaluative organization also emerged for state self-esteem such that compartmentalized individuals reported lower state selfesteem, $\beta=-.14, p<.05$. As predicted, the main effect of evaluative organization was qualified by its interaction with social rejection condition, $\beta=-.20, p<.05$. Predicted values for this interaction are presented in Figure 3. Because hypotheses concerned the interaction of evaluative organization and social rejection condition, 


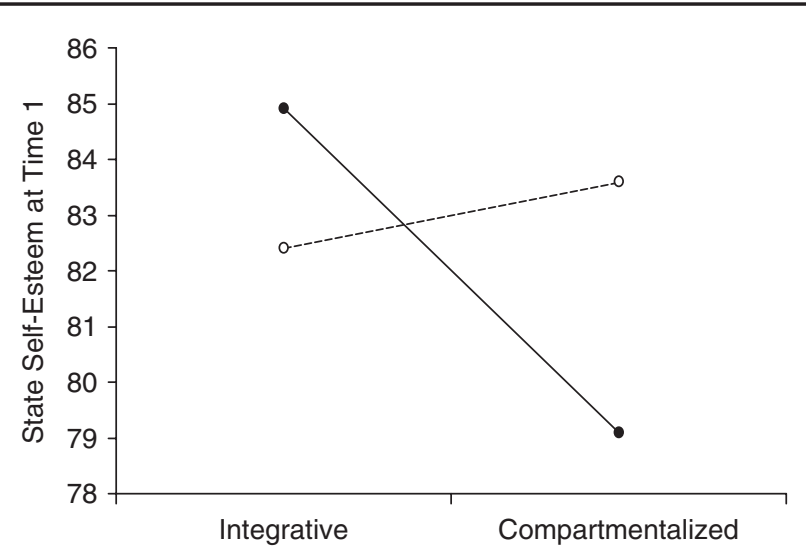

Evaluative Organization

--o- Accepted $\rightarrow$-Rejected

Figure 3 Adjusted predicted values for state self-esteem at Time 1, illustrating the interaction of evaluative organization (at values 1 standard deviation above and below the mean) and social rejection condition.

these regression analyses were followed by the simple slopes tests recommended by Aiken and West (1991). These tests specifically examined whether the regression slopes for evaluative organization were significantly different from zero for the social rejection and social acceptance conditions. Simple slopes test found that evaluative organization was a significant predictor of state selfesteem for individuals in the social rejection condition, $\beta=-.26, p<.01$, such that compartmentalized individuals reported significantly lower state self-esteem than integrative individuals. Evaluative organization was not a significant predictor of state self-esteem for individuals in the social acceptance condition, $\beta=.05$, ns.

A similar analysis examined perceived social rejection at Time 1 . For this analysis, main effects emerged for trait self-esteem, $\beta=-.30, p<.01$, and social rejection condition, $\beta=.24, p<.01$. An interaction of evaluative organization and social rejection condition also emerged, $\beta=.22, p<.05$. Predicted values for this interaction are shown in Figure 4. Simple slopes tests confirmed that evaluative organization was associated with perceived rejection for individuals in the social rejection condition, $\beta=.21, p<.05$, such that compartmentalized individuals reported higher levels of perceived rejection than integrative individuals. Evaluative organization was not associated with perceived rejection for individuals in the acceptance condition, $\beta=-.12$, ns.

\section{Time 2: 1 Hour Following Social}

Rejection or Acceptance

The moderating effect of self-concept structure on reactions to the social rejection manipulation was exam-

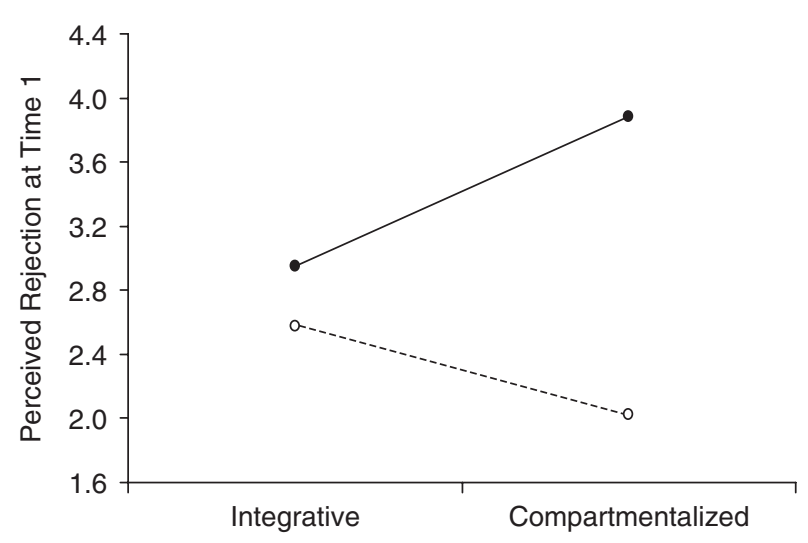

Evaluative Organization

$-\circ$ - Accepted $\rightarrow$ Rejected

Figure 4 Adjusted predicted values for perceived rejection at Time 1 , illustrating the interaction of evaluative organization (at values 1 standard deviation above and below the mean) and social rejection condition.

ined at Time 2 to determine whether effects that emerged immediately following the manipulation would persist and whether new effects would emerge over time. For state self-esteem, a main effect of trait self-esteem was found such that individuals with high levels of self-esteem continued to report high levels of state self-esteem at Time $2, \beta=.59, p<.001$. However, no other effects emerged for state self-esteem at Time 2 . For perceived social rejection, a main effect for trait self-esteem also emerged such that individuals with low levels of selfesteem continued to report high levels of perceived rejection at Time $2, \beta=-.28, p<.01$. No other main effects or interactions emerged for perceived rejection at Time 2 .

\section{Time 3: Daily Ratings (10 p.m.)}

These measures of state self-esteem and perceived rejection were collected after participants had been debriefed as to the nature of the Cyberball acceptance and rejection manipulation. It is important to note that these measures were not included in the daily measures used to derive the measure of self-esteem instability. Of interest, consistent with the Time 1 analysis of state selfesteem, there were significant main effects for evaluative organization, $\beta=-.20, p<.03$, and trait self-esteem, $\beta=.55, p<.001$. The main effect of evaluative organization was qualified by its interaction with social rejection condition, $\beta=-.19, p<.05$. The predicted values for this interaction are similar to those presented in Figure 3. As in the Time 1 analysis, simple slopes tests for this analysis found that evaluative organization was associated with state self-esteem for individuals in the social rejection condition, $\beta=-.33, p<.01$, but not for 
individuals in the social acceptance condition, $\beta=.09$, $n s$. No other effects emerged for state self-esteem at Time 3. Also consistent with the results from Time 1, the interaction of evaluative organization and social rejection condition emerged at Time 3 for perceived social rejection, $\beta=.30, p<.02$. The predicted values for this interaction are similar to those presented in Figure 4. As in the Time 1 analysis, simple slopes tests for this analysis found that evaluative organization was associated with perceived rejection for individuals in the social rejection condition, $\beta=.32, p<.05$, but not for individuals in the social acceptance condition, $\beta=-.13$, $n s$. No other effects reached conventional levels of significance for perceived social rejection at Time 3 .

\section{Discussion}

The sensitivity of compartmentalized individuals to social rejection was demonstrated by their lower levels of state self-esteem and higher levels of perceived rejection following the laboratory manipulation. Of interest, this effect was obtained immediately after the rejection manipulation and again at 10 p.m. but not 1 hour following the manipulation. One possibility is that the self-description measures completed between the initial state self-esteem ratings and the 1-hour assessment (which were not intended to be relevant to the goals of the present study) constituted a form of self-affirmation, activating positive self-aspects prior to the second assessment of state selfesteem. Of interest, the fact that participants were debriefed at the end of the laboratory session did not prevent self-esteem reactivity later that night. This could be an example of perseverance (Ross, Lepper, \& Hubbard, 1975). Alternatively, by 10 p.m., perhaps only the past experience of feeling rejected is important for an individual's feeling of self-esteem, regardless of explanations for that experience provided after the fact.

\section{GENERAL DISCUSSION}

The present results suggest that the self-esteem of compartmentalized individuals may be characterized as less stable than the self-esteem of integrative individuals. Study 1 found that evaluative organization was associated with self-esteem stability for individuals with high levels of trait self-esteem. Specifically, integrative individuals with relatively high levels of trait self-esteem displayed especially stable state self-esteem throughout a 1- to 2-week period. Presumably, the unstable self-esteem of positive compartmentalized individuals reflected their extreme reactions to daily events. This process was supported by daily events analyses, which indicated that the state self-esteem of compartmentalized individuals fluctuated along with the positive or negative events of the day. A similar result was obtained in Study 2 for the experience of social rejection in the laboratory.

Although not explicitly tested here, the hypothesized explanation for the instability of compartmentalized self-concepts is the activation of purely positive or purely negative attributes associated with evaluatively compartmentalized self-aspects. When purely positive self-aspects are activated, then compartmentalized individuals feel extremely good; when purely negative selfaspects are activated, these individuals feel extremely bad. Some people with good coping skills may be extremely successful at creating and maintaining salient positive compartments under conditions of stress (Showers et al., 1998). However, the present studies suggest that the typical compartmentalized individual in fact experiences substantial fluctuations in self-esteem in response to everyday events.

We have termed these fluctuations in self-esteem a "hidden vulnerability" of compartmentalized organization. Although individuals may be either positively compartmentalized or negatively compartmentalized, positive compartmentalization is believed to be more common (Showers, 2002). Positive compartmentalization is typically associated with positive mood and high self-esteem (with negative content held constant). However, such findings may obscure short-lived sensitivities to negative events (the instability demonstrated here) or longerlived effects such as dramatic shifts from positive to negative compartmentalization (cf. Showers \& ZeiglerHill, 2004).

Previous research on self-esteem instability links unstable self-esteem to inconsistency in self-knowledge (Kernis, Paradise, Whitaker, Wheatman, \& Goldman, 2000). Individuals with low self-concept clarity or highly differentiated self-concepts are believed to possess unstable self-esteem because their impoverished self-concept forces them to be more reliant on their immediate contexts for cues concerning their feelings of self-worth. Functionally similar inconsistencies may exist within compartmentalized structures. Because evaluative organization is concerned with the valence of specific self-beliefs, a compartmentalized self-concept is, by its very definition, likely to be evaluatively inconsistent across self-aspects. That is, because of the segregation of positive and negative attributes, individuals with compartmentalized self-concept structures may have greater variability in evaluations between self-aspects than individuals with integrative self-concepts. Individuals with integrative self-concept structures, on the other hand, may have inconsistencies within a particular self-aspect. For example, an individual with an integrative self-concept structure may consider the self to be shy but fun during social interactions. The fact that 
these self-beliefs are contained within the same selfaspect suggests that this integrative individual has reached some resolution of the inconsistency between these oppositely valenced self-beliefs.

It should be noted that the explanations presented for the current findings are based on a process model that assumes that evaluative organization is a relatively stable feature of the individual that exists prior to potentially self-relevant events and influences reactions to these events. However, the data in the present studies cannot rule out the possibility that the direction of causality may be either bidirectional or reversed. For example, Larsen and Diener (1987) provided an alternative conceptualization of structural effects that suggests that the tendency to experience extreme and variable emotional states may actually determine the structure of the selfconcept. This alternative model implies that individuals with stronger affective reactions may structure their selfrepresentations in a manner that tends to generate the higher levels of affect they desire. For example, an individual who desires intense emotions may construct a simple life organized around only a few self-aspects such as being a parent and spouse. By organizing life in this manner, self-esteem is likely to be very dependent on relationships with children and spouse. When this person feels loved and accepted by the family, the result may be very high self-esteem; however, feelings of extremely low self-esteem may be experienced on those occasions when the person does not feel loved and accepted. If necessary, it seems that the intensity and variability of emotional experiences could be reduced by increasing the complexity of life (e.g., by focusing greater attention on professional life). Of course, it is also possible that self-concept structure and unstable self-esteem are both by-products of some third variable (Emmons \& King, 1989). For example, certain neurologically based memory deficiencies may lead individuals to base their thoughts, feelings, and behaviors almost completely on what is happening in the present (Lumsden, 1993). It is possible that both compartmentalization and unstable self-esteem are due to this sort of time-frame truncation. This is a direction for future research.

One limitation of the present studies is that the daily reports of events and state self-esteem were not time stamped, leaving open the possibility that some of the participants' reports were completed retrospectively within each 3- to 4-day period. Thus, it is possible that integrative individuals appear to have more stable selfesteem because they are biased in any retrospective reporting. If the observed effects on state self-esteem are in fact due to differential retrospective reporting, then the daily events analyses may simply indicate that individuals with integrative self-concept structures recover from positive and negative events more quickly so that they recall the impact on their state self-esteem as more muted than it actually was. However, this explanation is contradicted by the results of Study 2, in which the same stable response is observed for integrative individuals with immediate reporting. Thus, Study 2 suggests that time stamping would not have altered the results of Study 1 (cf. Green, Rafaeli, Bolger, Shrout, \& Reis, 2006). Another problem with the retrospective bias explanation of Study 1 is that self-concept structure was not correlated with the number of daily reports returned or with the number of positive or negative events $(B s<$ $.37, n s)$. It seems likely that if there were a retrospective bias in reports of self-esteem, there would be a concomitant bias (either upward or downward) in reports of events, but this did not occur.

Previous studies have established that positively compartmentalized individuals tend to have relatively high levels of self-esteem and positive mood (e.g., Showers, 1992; Showers et al., 1998). However, these studies have relied exclusively on self-report measures of current adjustment, which leaves open the possibility that positively compartmentalized individuals inflate their self-reports of adjustment. Essentially, compartmentalization may reflect a tendency to bolster self-esteem and mood by denying or isolating information that threatens feelings of self-worth or mood. This tendency may be manifest in responses to self-report measures of psychological adjustment. Thus, some of the benefits that are believed to be associated with compartmentalization-such as high self-esteem-may not reflect true psychological adjustment. This perspective is supported by results from the present studies showing that individuals with compartmentalized self-concept structures tend to have self-esteem that is less stable than the selfesteem of integrative individuals.

\section{NOTES}

1. The Implicit Self-Evaluation Scale (ISES; Pelham \& Hetts, 1999) and the Contingencies of Self-Worth Scale (CSWS; Crocker, Luhtanen, Cooper, \& Bouvrette, 2003) also were included in the present studies. The ISES was administered daily with the state selfesteem and daily events measures. The zero-order correlation between evaluative organization and the person-mean on the ISES did not reach conventional levels of significance for either Sample A $(r=-.07$, $n s)$ or Sample B $(r=-.07, n s)$. Only participants in Sample B completed the CSWS in the first laboratory session. The correlation between the CSWS composite score and evaluative organization showed that individuals with compartmentalized self-concept structures reported more contingent self-esteem, $r(136)=.20, p<.05$.

2. It was surprising to find that even though participants in Sample A were assessed more often than participants in Sample B (twice per day for 14 days vs. once per day for 7 days), participants in Sample A reported less stable self-esteem (i.e., a greater standard deviation) than the participants in Sample B. One possible explanation is that the longer diary period for Sample A (which also included more weekend days) increased the likelihood that extreme events or substantial changes in self-esteem would occur. The variability of evaluative organization, 
differential importance, proportion of negative attributes, and trait selfesteem was not significantly different across samples, Levene's Fs $(1$, $225)<.74, p s>.39$.

3. Because of the conceptual overlap between these findings and the predictions that would stem from a self-complexity model (Linville, $1985,1987)$, the daily events analyses were repeated with terms testing the effects of self-complexity (as assessed by Linville's original measure, Scott's $\mathrm{H}$ ) and its interactions with positive and negative events. No effects involving self-complexity were significant and including these terms did not change the significant effects for phi that are reported here.

\section{REFERENCES}

Aiken, L. S., \& West, S. G. (1991). Multiple regression: Testing and interpreting interactions. Thousand Oaks, CA: Sage.

Baumeister, R. F., \& Leary, M. R. (1995). The need to belong: Desire for interpersonal attachments as a fundamental human motivation. Psychology Bulletin, 117, 497-529.

Baumeister, R. F., \& Tice, D. M. (1990). Anxiety and social exclusion. Journal of Social and Clinical Psychology, 9, 165-195.

Berglas, S., \& Jones, E. E. (1978). Drug choice as a self-handicapping strategy in response to noncontingent success. Journal of Personality and Social Psychology, 36, 405-417.

Blaskovich, J., \& Tomaka, J. (1991). Measures of self-esteem. In J. P. Robinson, P. R. Shaver, \& L. S. Wrightsman (Eds.), Measures of personality and social psychological attitudes (pp. 115-160). San Diego, CA: Academic Press.

Bryk, A. S., \& Raudenbush, S. W. (1992). Hierarchical linear models. Newbury Park, CA: Sage.

Bryk, A. S., Raudenbush, S. W., \& Congdon, R. T. (1998). HLM4. Chicago: Scientific Software International.

Butler, A. C., Hokanson, J. E., \& Flynn, H. A. (1994). A comparison of self-esteem lability and low trait self-esteem as vulnerability factors for depression. Journal of Personality and Social Psychology, 66, 166-177.

Campbell, J. D. (1990). Self-esteem and clarity of the self-concept. Journal of Personality and Social Psychology, 59, 538-549.

Cohen, J., Cohen, P., West, S. G., \& Aiken, L. S. (2003). Applied multiple regression/correlation analysis for the behavioral sciences (3rd ed.). Mahwah, NJ: Lawrence Erlbaum.

Cramer, H. (1974). Mathematical methods of statistics. Princeton, NJ: Princeton University Press. (Original work published 1945)

Crocker, J., Luhtanen, R. K., Cooper, M. L., \& Bouvrette, A. (2003). Contingencies of self-worth in college students: Theory and measurement. Journal of Personality and Social Psychology, 85, 894908.

Curran, P. J., Bauer, D. J., \& Willoughby, M. T. (2006). Testing and probing within-level and between-level interactions in hierarchical linear models. In C. S. Bergeman \& S. M. Boker (Eds.), The Notre Dame series on quantitative methodology, Volume 1: Methodological issues in aging research (pp. 99-129). Mahwah, NJ: Lawrence Erlbaum.

DeLongis, A., Folkman, S., \& Lazarus, R. S. (1988). The impact of daily stress on health and mood: Psychological and social resources as mediators. Journal of Personality and Social Psychology, 54, 486-495.

Emmons, R. A., \& King, L. A. (1989). Personal striving differentiation and affective reactivity. Journal of Personality and Social Psychology, 56, 478-484.

Everitt, B. S. (1977). The analysis of contingency tables. London: Chapman and Hall.

Green, A. S., Rafaeli, E., Bolger, N., Shrout, P. E., \& Reis, H. T. (2006). Paper or plastic? Data equivalence in paper and electronic diaries. Psychological Methods, 11, 87-105.

Kernis, M. H. (2003). Toward a conceptualization of optimal selfesteem. Psychological Inquiry, 14, 1-26.

Kernis, M. H., Cornell, D. P., Sun, C. R., Berry, A. J., \& Harlow, T. (1993). There's more to self-esteem than whether it is high or low: The importance of stability of self-esteem. Journal of Personality and Social Psychology, 65, 1190-1204.
Kernis, M. H., Grannemann, B. D., \& Barclay, L. C. (1989). Stability and level of self-esteem as predictors of anger arousal and hostility. Journal of Personality and Social Psychology, 56, 1013-1023.

Kernis, M. H., Greenier, K. D., Herlocker, C. E., Whisenhunt, C. R. \& Abend, T. A. (1997). Self-perceptions of reactions to doing well or poorly: The roles of stability and level of self-esteem. Personality and Individual Differences, 22, 845-854.

Kernis, M. H., Paradise, A. W., Whitaker, D. J., Wheatman, S. R., \& Goldman, B. N. (2000). Master of one's psychological domain? Not likely if one's self-esteem is unstable. Personality and Social Psychology Bulletin, 26, 1297-1305.

Kernis, M. H., \& Waschull, S. B. (1995). The interactive roles of stability and level of self-esteem: Research and theory. In M. P. Zanna (Ed.), Advances in experimental social psychology (Vol. 27, pp. 93-141). San Diego, CA: Academic Press.

Larsen, R. J., \& Diener, E. (1987). Affect intensity as an individual difference characteristic: A review. Journal of Research in Personality, 21, 1-39.

Leary, M. R., Tambor, E. S., Terdal, S. K., \& Downs, D. L. (1995). Self-esteem as an interpersonal monitor: The sociometer hypothesis. Journal of Personality and Social Psychology, 68, 518-530.

Linville, P. W. (1985). Self-complexity and affective extremity: Don't put all of your eggs in one basket. Social Cognition, 3, 94-120.

Linville, P. W. (1987). Self-complexity as a cognitive buffer against stress-related illness and depression. Journal of Personality and Social Psychology, 52, 663-676.

Lumsden, E. A. (1993). Borderline personality disorder: A consequence of experiencing affect within a truncated time frame? Journal of Personality Disorders, 7, 265-274.

Markus, H., \& Wurf, E. (1987). The dynamic self-concept: A social psychological perspective. In M. R. Rosenzweig \& L. W. Porter (Eds.), Annual review of psychology (Vol. 38, pp. 299-337). Palo Alto, CA: Annual Reviews.

Morf, C. C., \& Rhodewalt, F. (2001). Unraveling the paradoxes of narcissism: A dynamic self-regulatory processing model. Psychological Inquiry, 12, 177-196.

Murray, S. L., \& Holmes, J. G. (1999). The (mental) ties that bind: Cognitive structures that predict relationship resilience. Journal of Personality and Social Psychology, 77, 1228-1244.

Newman, L. S., \& Wadas, R. F. (1997). When stakes are higher: Selfesteem instability and self-handicapping. Journal of Social Behavior and Personality, 12, 217-232.

Nezlek, J. B., \& Gable, S. L. (2001). Depression as a moderator of relationships between positive daily events and day-to-day psychological adjustment. Personality and Social Psychology Bulletin, $27,1692-1704$

Nezlek, J. B., \& Plesko, R. M. (2003). Affect- and self-based models of relationships between daily events and daily well-being. Personality and Social Psychology Bulletin, 29, 584-596.

Pelham, B. W., \& Hetts, J. J. (1999). Implicit and explicit personal and social identity: Toward a more complete understanding of the social self. In T. Tyler \& R. Kramer (Eds.), The psychology of the social self (pp. 115-143). Mahwah, NJ: Lawrence Erlbaum.

Pelham, B. W., \& Swann, W. B., Jr. (1989). From self-conceptions to self-worth: On the sources and structure of global self-esteem. Journal of Personality and Social Psychology, 57, 672-680.

Raudenbush, S. W., \& Bryk, A. S. (2002). Hierarchical linear models: Applications and data analysis methods. London: Sage Ltd.

Rhodewalt, F., Madrian, J. C., \& Cheney, S. (1998). Narcissism, selfknowledge organization, and emotional reactivity: The effect of daily experiences on self-esteem and affect. Personality and Social Psychology Bulletin, 24, 75-87.

Rosenberg, M. (1965). Society and the adolescent self-image. Princeton, NJ: Princeton University Press.

Rosenthal, R., \& Rosnow, R. L. (1984). Essentials of behavioral research: Methods and data analysis. New York: McGraw-Hill.

Ross, L., Lepper, M. R., \& Hubbard, M. (1975). Perseverance in self perception and social perception: Biased attributional processes in the debriefing paradigm. Journal of Personality and Social Psychology, 32, 880-892.

Schwartz, R. M., \& Garamoni, G. L. (1986). A structural model of positive and negative states of mind: Asymmetry in the internal 
dialogue. In P. C. Kendall (Ed.), Advances in cognitive-behavioral research and therapy (Vol. 5, pp. 1-62). New York: Academic Press.

Showers, C. J. (1992). Compartmentalization of positive and negative self-knowledge: Keeping bad apples out of the bunch. Journal of Personality and Social Psychology, 62, 1036-1049.

Showers, C. J. (1995). The evaluative organization of self-knowledge: Origins, processes, and implications for self-esteem. In M. H. Kernis (Ed.), Efficacy, agency, and self-esteem (pp. 101-120). New York: Plenum.

Showers, C. J. (2000). Self-organization in emotional contexts. In J. P. Forgas (Ed.), Feeling and thinking: The role of affect in social cognition (pp. 283-307). Cambridge, UK: Cambridge University Press.

Showers, C. J. (2002). Integration and compartmentalization: A model of self-structure and self-change. In D. Cervone \& W. Mischel (Eds.), Advances in personality science (pp. 271-291). New York: Guilford.

Showers, C. J., Abramson, L. Y., \& Hogan, M. E. (1998). The dynamic self: How the content and structure of the self-concept change with mood. Journal of Personality and Social Psychology, $75,478-493$.

Showers, C. J., \& Kevlyn, S. B. (1999). Organization of knowledge about a relationship partner: Implications for liking and loving. Journal of Personality and Social Psychology, 76, 958-971.

Showers, C. J., \& Kling, K. C. (1996). Organization of self-knowledge: Implications for recovery from sad mood. Journal of Personality and Social Psychology, 70, 578-590.
Showers, C. J., Limke, A., \& Zeigler-Hill, V. (2004). Self-structure and self-change: Applications to psychological treatment. Behavior Therapy, 35, 167-184.

Showers, C. J., \& Zeigler-Hill, V. (2003). Organization of selfknowledge: Features, functions, and flexibility. In M. R. Leary \& J. Tangney (Eds.), Handbook of self and identity (pp. 47-67). New York: Guilford.

Showers, C. J., \& Zeigler-Hill, V. (2004). Organization of partner knowledge: Relationship outcomes and longitudinal change. Personality and Social Psychology Bulletin, 30, 1198-1210.

Showers, C. J., \& Zeigler-Hill, V. (in press). Pathways among selfknowledge and self-esteem: How are self-esteem and self-knowledge linked? Are these links direct or indirect? In M. H. Kernis (Ed.), Self-esteem issues and answers: A source book of current perspectives. New York: Psychology Press.

Showers, C. J., Zeigler-Hill, V., \& Limke, A. (2006). Self-structure and emotional maltreatment: Successful compartmentalization and the struggle of integration. Journal of Social and Clinical Psychology, 25, 473-507.

Williams, K. D., Cheung, C. K. T., \& Choi, W. (2000). Cyberostracism: Effects of being ignored over the Internet. Journal of Personality and Social Psychology, 79, 748-762.

Zajonc, R. B. (1960). The process of cognitive tuning in communication. Journal of Abnormal and Social Psychology, 61, 159-167.

Received February 21, 2006

Revision accepted July 27, 2006 